\title{
Epoxidation of some vegetable oils and their hydrolysed products with peroxyformic acid - optimised to industrial scale
}

\author{
Padmasiri K. Gamage ${ }^{1}$, Micheal O'Brien ${ }^{1}$ and Laleen Karunanayake ${ }^{2 *}$ \\ ${ }^{1}$ London Metropolitan Polymer Centre, London Metropolitan University, Holloway Road, London N7 8DB,UK. \\ 2 Department of Chemistry, Faculty of Applied Science, University of Sri Jayewardenepura, Gangodawila, Nugegoda.
}

\begin{abstract}
Epoxidation increases the polarity and the stability of vegetable oils improving their compatibility with polymers such as polyvinyl chloride (PVC). Hence, epoxidized vegetable oils can be used as plasticizers/stabilizers in the polymer industry. The objective of this work is to establish a method of epoxidised vegetable oils on a relatively large scale which could be scaled up to industrial scale. The fatty acid composition of rubber seed oil, Madhuca oil (Mee oil) and Neem oil were determined by gas chromatography-mass spectrometry (GC-MS). These oils and their hydrolysed products were epoxidized successfully by peroxyformic acid generated 'in situ' by reacting formic acid (methanoic acid) with hydrogen peroxide. The reaction time was optimised and the possibility of controlling the level of epoxidation was attempted by limiting the reagents; hydrogen peroxide and methanoic acid. The epoxidation was confirmed by iodine value, fourier transform infrared spectroscopy (FTIR), nuclear magnetic resonance (NMR) and thin layer chromatography (TLC) analysis. Twelve epoxidised oil derivatives were prepared by optimised conditions on a comparatively large scale without solvent extraction procedures. Products were characterised for iodine value, oxirane content, density and molar masses. Further, solubility parameter values of prepared oil derivatives were determined. It was found that more than $80 \%$ of the reaction was completed within three hours at $60^{\circ} \mathrm{C}$. The level of epoxidation could be controlled reasonably by limiting the reagents. The solubility parameter values were comparable with those of conventional plasticizers used in the PVC industry.
\end{abstract}

Keywords: Epoxidation, peroxyformic acid, solubility parameters, vegetable oil.

\section{INTRODUCTION}

Vegetable oils are triglycerides in which $\mathrm{C}_{18}$ carboxylic acids are dominant. Some of the fatty acids derived from these glycerides are unsaturated; those typically contain stearic, oleic, linoleic and linolenic acids in varying amounts. Three of these are unsaturated acids namely oleic (18:1), linoleic (18:2) and linolenic (18:3) (Figure 1) 1 .

Epoxidation of fatty acids is a reaction of a carbon - carbon double bond with active oxygen, which results in the addition of an oxygen atom, converting the original double bond into a three membered epoxide (oxirane) ring. In general, olefins can be epoxidised with various per-acids, of which m-chloroperbenzoic acid has been the most often used ${ }^{2}$. Other per acids, especially per acetic and per benzoic, have also been used. Trifluoroperacetic acid and 3,5-dinitroperoxybenzoic acids are reported to be particularly reactive ones. In situ epoxidation of rubber seed oil with $\mathrm{H}_{2} \mathrm{O}_{2}$ /ethanoic acid has been reported in $1971^{3}$. It was found that molar ratio of reactants, temperature and catalysts are critical in obtaining an acceptable oxirane content. The reaction was found to be overall second order and a one step mechanism (Figure 2) has been proposed ${ }^{2}$. Epoxidation of vegetable oils on an industrial scale is most frequently carried out with peroxoacetic acid and peroxoformic acid due to the low cost. Those per-acids are generated in the reaction mixture 'in situ' reacting the relevant acid with hydrogen peroxide under pre-selected conditions. Kinetic studies of epoxidation of soybean oil with peroxoacetic acid and peroxoformic acid have been reported and found to be pseudo-first order with respect to both double bonds as well as peroxo acid ${ }^{4}$. Previous studies have also investigated the kinetics of epoxidation of rubber seed oil by peroxoacetic acid generated 'in situ' and have shown that the negligible oxirane cleavage and almost complete epoxidation could be achieved by these 
techniques. Further, enthalpy, entropy and activation energy of epoxidation of rubber seed oil have been reported $^{5}$. The use of cation exchange resin as a catalyst in the peroxoacetic acid epoxidation of vegetable oils has also been reported ${ }^{6}$, albeit the method seems to be tedious
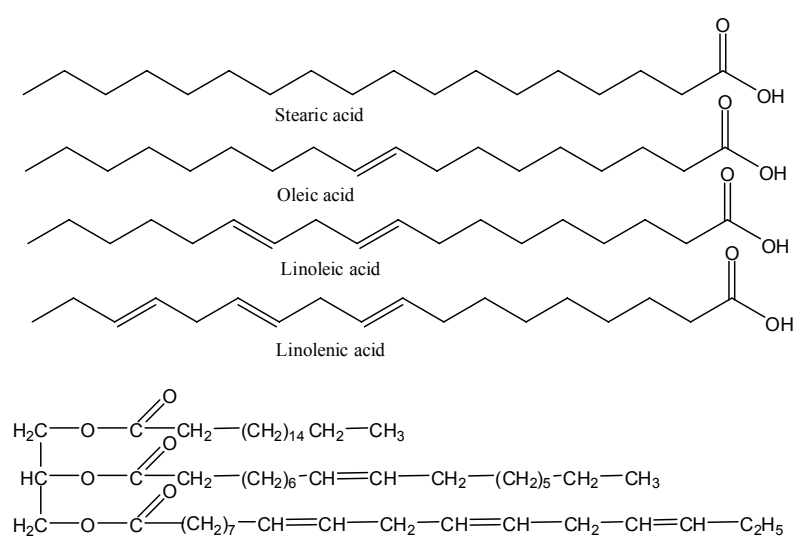

Figure 1: Chemical structures of stearic, oleic, linoleic and linolenic acids and a structure of a possible triglyceride

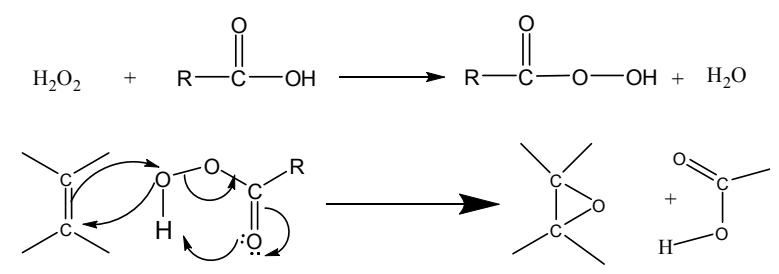

Figure 2: Mechanism of epoxidation ${ }^{4}$

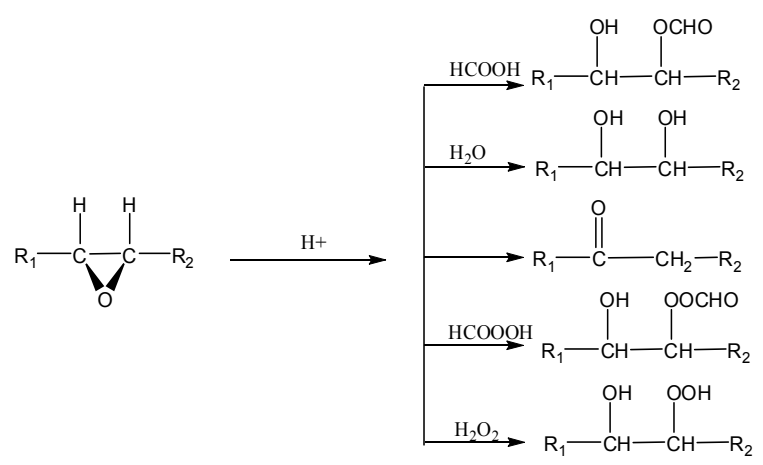

Figure 3: Possible side reactions of epoxides
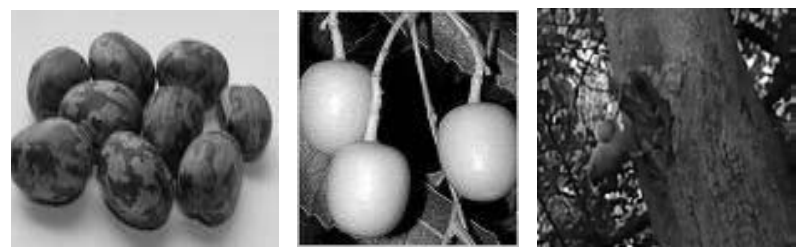

Figure 4: Rubber seeds (left) neem fruits (middle), mee fruits (right) due to difficulty of separating the product from the resin. However, the epoxidation of a vegetable oil must be carried out with great care to prevent any possible side reactions. Figure 3 shows some possible side reactions of the oxirane ring.

Most of the aforementioned methods of epoxidation of vegetable oils explained laboratory scale preparations and some required long reaction times and use of organic solvents. Possibilities of utilisation of epoxidised products of vegetable oils in polyvinyl chloride (PVC) formulations were extensively documented ${ }^{7-15}$. Therefore, there is necessity of a comprehensive method of epoxidation, which is easy, simple and cost effective; if epoxidised vegetable oils are to be employed in industrial applications as such. In this study an attempt was made to ascertain an unfailing experimental procedure, which is economically viable for the epoxidation of vegetable oils for industrial uses. Three vegetable oils, namely rubber seed oil (RSO), neem oil (NMO) and mee oil or Madhuca oil (MO) were selected for this study, aiming development of value added products from these locally available renewable resources, which are non-toxic and under exploited. Controlling the level of epoxidation and the effect of the reaction time on level of epoxidation were also investigated to optimise a reaction protocol. Furthermore, molar masses, solubility parameters $(\delta)$ and $\chi$ values were also evaluated for virgin and epoxidised oils. Here, we consider their expedient to briefly describe the nature of these oils.

Natural rubber (Hevea brasiliensis) is a plantation crop in Sri Lanka and is cultivated on both large and small scales. The oil extractable from seed is rich in useful saturated and unsaturated fatty acids. Neem oil is a vegetable oil pressed from the fruits and seeds of neem (Azadirachta indica), an evergreen tree that is endemic to the Indian subcontinent. It is perhaps the most important of the commercially available products of neem. However, all parts of the neem tree (leave, bark, etc.) are considered equally important in the field of indigenous medicine, and is used for a wide range of afflictions (skin diseases, inflammations and fevers). Neem oil is used for preparing cosmetics such as soap, hair products, body hygiene creams, hand creams, etc. Formulations utilising neem oil are also found in a broad range of products such as bio-pesticides and insecticides ${ }^{16}$. Mee oil is another vegetable oil pressed from the seeds of mee. The tree belongs to the family Sapotaceae; and there are two major species of the genus, Madhuca longifolia and M. indica. Though mee is not intentionally cultivated, it is widely distributed in tropical forests. The uses of products of the mee tree are still limited to some Ayurvedic medical applications. Figure 4 represents seeds of rubber, and fruits of neem and mee. 


\section{METHODS AND MATERIALS}

The rubber seed oil used in this study was obtained from a local manufacturing agent in Sri Lanka and neem and Madhuca oils were purchased from D. Peiris \& Co. Ltd., Colombo. Hydrogen peroxide used was from East Anglia Chemicals (40\% w/v) and Fisher Chemicals (30\%w/v) and was standardised before using. Analytical reagent grade ethanoic acid (formic acid) from Fisher Scientific was used after standardisation. All other chemicals and solvents used were of the technical grade and used without further purification. Distilled solvents were used for thin layer chromatography (TLC) analysis.

Characterisation of oils/oil derivatives: Fatty acid profiles of oils were obtained by using a Varian star 1 gas chromatography - mass spectrometry (GC-MS) instrument. For this purpose, oils were methylated according to the standard procedure using $\mathrm{BF}_{3} /$ methanol solution $^{17}$. Fourier transform infrared spectroscopy (FTIR) spectra of virgin oils and epoxidised oils were recorded by a Thermo Nicolet AVATAR 320 FTIR spectrometer coupled with Ezominic software. A thin layer of sample was applied over a $\mathrm{NaCl}$ plate and the spectrum was recorded in the range 400-4000 $\mathrm{cm}^{-1}$. Nuclear magnetic resonance (NMR) spectra were recorded using
BRUCKER AVANCE 500 NMR spectrophotometer. For NMR experiments frequencies of $500 \mathrm{MHz}$ and 125.7 $\mathrm{MHz}$ were used to record ${ }^{1} \mathrm{H}$ and ${ }^{13} \mathrm{C}$ spectra, respectively. The solutions used were prepared in deuterochloroform using tetramethyl silane (TMS) as the reference. Viscosity measurements were made using a Brookfield model RV-DVE 230 viscometer. An Abbey refractometer was used to measure the refractive indices of virgin oils. Iodine value and oxirane oxygen content of oils and their derivatives were determined using standard methods ${ }^{17}$. A standard procedure ${ }^{18}$ was used to evaluate saponification values of oils. Silica coated aluminium TLC plates were used for TLC analysis. The solvent used was a mixture of hexane and $\mathrm{CH}_{2} \mathrm{Cl}_{2}$ in 2:5 ratio, to which a few drops of glacial acetic acid were added. Plates were visualized in an iodine chamber.

\section{Epoxidation of oils}

a) small scale epoxidation: This was carried out according to the procedure described by F.E.Okieiman et $a l^{19}$. Double bond equivalent (moles of unsaturation per gram of oil) was calculated for oils using respective iodine values. The molar ratio between moles of double bonds to $\mathrm{HCOOH}$ to $\mathrm{H}_{2} \mathrm{O}_{2}$ peroxide was kept as 2:1:4, respectively, to achieve $100 \%$ level of epoxidation of

Table 1: Molar ratio of reagents for different levels of epoxidation

\begin{tabular}{cccc}
\hline $\begin{array}{c}\text { Expected level of } \\
\text { epoxidation }\end{array}$ & Mol of unsaturation & Mol of $\mathrm{HCOOH}$ & Mol of $\mathrm{H}_{2} \mathrm{O}_{2}$ \\
\hline $100 \%$ & 2 & 1.00 & 4 \\
$50 \%$ & 2 & 0.50 & 2 \\
$25 \%$ & 2 & 0.25 & 1 \\
\hline
\end{tabular}

Table 2: Reported properties and fatty acid profiles of rubber seed, Neem and mee oils

\begin{tabular}{lccc}
\hline Fatty acid & \multicolumn{3}{c}{$\%$ by weight } \\
\cline { 2 - 4 } & Rubber seed oil ${ }^{19}$ & Neem oil ${ }^{25}$ & Mee oil ${ }^{26}$ \\
\hline Palmitic acid & 17.51 & 18 & 24.5 \\
Stearic acid & 4.82 & 20 & 22.7 \\
Oleic acid & 25.33 & 41 & 37.0 \\
Linoleic acid & 37.5 & 20 & 14.3 \\
Linolenic acid & 14.21 & 1 & - \\
Others & 0.63 & - & 1.5 \\
Property & Rubber seed oil 27 & Neem oil & Mee oil ${ }^{28}$ \\
Specific gravity & 0.916 & $0.9087-0.9186$ & 0.96 \\
Viscosity (mm $\left.{ }^{2} / \mathrm{s}\right)$ & 76.4 & - & 24.58 \\
Flash point $\left({ }^{\circ} \mathrm{C}\right)$ & 198 & $>115$ & 232 \\
Saponification value & 206 & $193-204$ & $187-197^{26}$ \\
Iodine value & 136 & $68-76$ & $55-70^{26}$ \\
Acid value & 53 & - & 38 \\
Refractive index & 1.47 & $1.4617-1.4627$ & $1.4590-1.4611$ \\
\hline
\end{tabular}


oils/oil derivatives. The mass of oil equivalent to 0.214 moles of double bonds was used. At the end of the reaction, the product was extracted to sufficient amount of ethyl acetate. When virgin oils were epoxidised, the ethyl acetate layer was neutralised with an accurate amount of solid $\mathrm{NaHCO}_{3}$. The epoxidised product of oil was isolated by rotary evaporation of dried acid free ethyl acetate layer, at $70^{\circ} \mathrm{C}$.

b) Large scale epoxidation: The oil/oil derivative $(1 \mathrm{~kg})$ was taken into a $5 \mathrm{~L}$ flask and the required amount of $\mathrm{HCOOH}$ was added. The mixture was cooled to $10^{\circ} \mathrm{C}$ and calculated amount of $\mathrm{H}_{2} \mathrm{O}_{2}$ equilibrated at $0-5^{\circ} \mathrm{C}$ was added from a separatory funnel (at a rate of $5 \mathrm{~mL} / \mathrm{min}$ ) for about $2 \frac{1}{2} \mathrm{~h}$. If the oil/oil derivative was a solid at room temperature, $\mathrm{H}_{2} \mathrm{O}_{2}$ was added at a temperature of about $30^{\circ} \mathrm{C}$. Thereafter, the temperature of the reaction mixture was raised to $50-60{ }^{\circ} \mathrm{C}$ and kept for about $3 \mathrm{~h}$ at this temperature range with continuous stirring. At the end of this period the entire mixture was transferred to a large vessel containing water and a calculated amount of solid $\mathrm{NaHCO}_{3}$. If the oil derivative was a hydrolysed product of oil that was prepared as in the procedure given in the section, $\mathrm{NaHCO}_{3}$ was not added. The mixture was then rinsed with water until free from acid. Finally, the product was stirred with saturated $\mathrm{NaCl}$ solution and the top water-free layer of oil derivative was isolated.

c) Optimising the reaction time: Epoxidation was carried out as described in, but aliquots of the reaction mixture were withdrawn at $2 \mathrm{~h}, 3 \mathrm{~h}, 4 \mathrm{~h}$, and $5 \mathrm{~h}$ time intervals after raising the temperature to $60{ }^{\circ} \mathrm{C}$ and proceeded in a similar way to isolate the product.

d) Controlling the level of epoxidation: The molar ratio of $\mathrm{HCOOH}$ and $\mathrm{H}_{2} \mathrm{O}_{2}$ were varied as indicated in Table 1 keeping the number of moles of double bonds constant. Required quantities were reacted as indicated in section a).

e) Hydrolysis of oils: In small scale hydrolysis, $20 \mathrm{~g}$ of oil were refluxed with $10 \% \mathrm{NaOH}(200 \mathrm{~mL})$ for about $30 \mathrm{~min}$. The semi-solid soap solution obtained was dissolved completely in hot water. The solution was acidified with dilute $\mathrm{H}_{2} \mathrm{SO}_{4}$ and the hydrolysed products of oil were extracted to $\mathrm{CH}_{2} \mathrm{Cl}_{2}$. The product was obtained by rotary evaporation of dried $\mathrm{CH}_{2} \mathrm{Cl}_{2}$ layer.

The hydrolysis reaction was carried out on a relatively large scale using $1 \mathrm{~kg}$ of oil according to the following procedure.

The oil sample $(1 \mathrm{~kg})$ was shaken with $10 \% \mathrm{NaOH}$ solution $(1000 \mathrm{~mL})$ for about $30 \mathrm{~min}$. The mixture was heated with stirring and allowed to cool. The semi-solid product was dissolved in warm water (portion wise) and acidified with conc. $\mathrm{H}_{2} \mathrm{SO}_{4}$. The oil layer was separated and washed with water until acid free. Finally the liquid was stirred with saturated $\mathrm{NaCl}$ solution. Then the top oil layer was isolated.

\section{RESULTS AND DISCUSSION}

\section{Initial characterisation of oils}

Fatty acid compositions of oils obtained from the literature for three oils are given in Table 2, while the data obtained

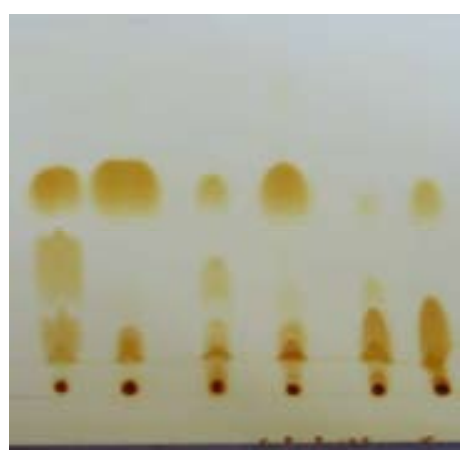

Figure 5: TLC of epoxidised and virgin oilsright to left VR, ER, VN, EN, VM, EM (E=epoxidized, $V=$ virgin, $\mathrm{N}=$ neem oil, $\mathrm{M}=\mathrm{mee}$ oil and $\mathrm{R}=$ rubber seed oil)
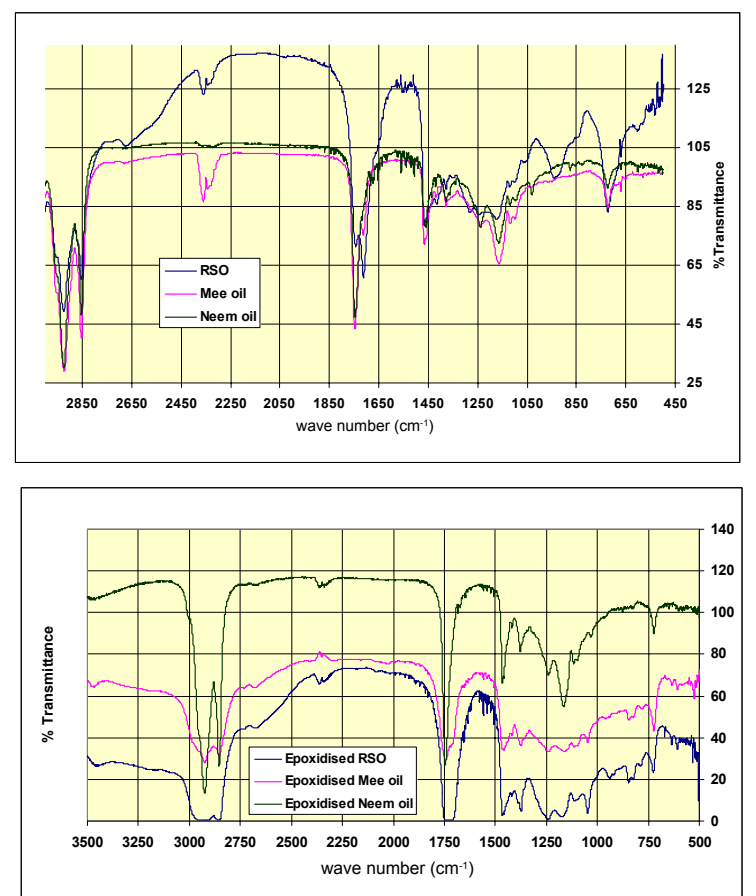

Figure 6: FTIR spectra of rubber seed oil, neem oil, mee oil and their epoxidised products 
Table 3: Fatty acid composition of oils

\begin{tabular}{lcccc}
\hline Fatty acid & \multicolumn{4}{c}{ Percentage composition } \\
\cline { 2 - 5 } & Soybean oil & Rubber seed oil & Neem oil & Mee oil \\
\hline Palmitic acid (16:1) & 11 & traces & 11 & 18 \\
Stearic acid (18:0) & 04 & traces & 14 & 25 \\
Oleic acid (18:1) & 23 & 33 & 42 & 40 \\
Linoleic acid (18:2) & 53 & 48 & 32 & 17 \\
Linolenic acid(18:3) & 08 & 19 & traces & traces \\
\hline
\end{tabular}

Table 4: Basic properties of oils

\begin{tabular}{lccc}
\hline Property & Rubber seed oil & Neem oil & Mee oil \\
\hline Appearance & blackish brown & greenish brown & pale yellow \\
Specific gravity & 0.9259 & 0.9586 & 0.9125 \\
Refractive index & 1.4650 & 1.4745 & 1.4610 \\
Iodine value & 120 & 109 & 62 \\
Saponification value & 191 & 177 & 195 \\
Viscosity (cP:21 $\left.{ }^{\circ} \mathrm{C}, 30 \mathrm{rpm}\right)$ & 173 & 157 & 203 \\
Mass of oil equivalent to one & & & 475 \\
mol of double bond $(\mathrm{g})$ & 203 & 344 & \\
\hline
\end{tabular}

using GC-MS are given in Table 3 and compared with the composition of soybean oil ${ }^{20}$. Soybean's epoxidised product is generally used in PVC formulations $\mathrm{s}^{21-23}$. Other pertinent properties of oils are delineated in Table 4 . The iodine values obtained for selected oils are slightly different from the reported values ${ }^{19,24-28}$. Depending on the growing site of the trees, and the maturity of the seeds, oils can vary greatly in iodine values. Typically, oils harvested from plants grown in cooler regions will have more double bonds and thus higher iodine values than those grown in warmer (tropical, subtropical) regions ${ }^{8}$. Lower iodine values are also possible due to the aerial oxidation of double bonds in the oil.

\section{Epoxidation of oils}

According to the procedure given in sections a) \& b), "in situ" epoxidation of oils/ oil derivatives was carried out in the molar ratio of 2:1:4 - double bonds: $\mathrm{HCOOH}$ : $\mathrm{H}_{2} \mathrm{O}_{2}$, respectively. The formation of the peroxo acid from the acid and hydrogen peroxide is reversible and the acid is regenerated after epoxidation of the double bonds. Hydrogen peroxide is consumed in the process of formation of peroxo acid and through the thermal decomposition. The excess of $100 \% \mathrm{~mol}$ of $\mathrm{H}_{2} \mathrm{O}_{2}$ relative to the double bonds was considered reasonable to attain $100 \%$ level of epoxidation. After completion of the reaction the acid regenerated should be removed from the system, as its presence will lead to epoxy ring opening, by side reactions. Therefore, $\mathrm{NaHCO}_{3}(\mathrm{~s})$ was added to the reaction mixture to neutralise the acid present, and being a weak base, $\mathrm{NaHCO}_{3}$ will not react towards ester linkages or epoxy rings. The same procedure was followed to epoxidise, hydrolysed products of oils; but in the case of removing the acid remaining in the reaction mixture, $\mathrm{NaHCO}_{3}$ cannot be used since carboxylic acid reacts with $\mathrm{NaHCO}_{3}$ to liberate $\mathrm{CO}_{2}(\mathrm{~g})$. Previous studies ${ }^{19}$ reported the use of moderate temperature of $60{ }^{\circ} \mathrm{C}$ in order to get the optimum yield of epoxidised rubber seed oil, since epoxy rings open up at higher temperature. Therefore, the reaction temperature was maintained between $50-60{ }^{\circ} \mathrm{C}$.

TLC analysis of epoxidised products and virgin oils are given in Figure 5. This suggests that some moderately polar compounds which were not observed in pure oils were present in all epoxidised products. The polarity of a compound increases with epoxidation and moderate polarity could have resulted from the epoxidised products because more polar compounds move less in a polar silica layer. The percentage reduction of iodine values (Tables 5 and 6 ) reveals that products obtained are almost $90 \%$ epoxidized. The slight variation can be attributed to experimental errors. If the reaction is carried out for further two or three hours, the extent of epoxidation would have reached nearly $100 \%$.

\section{FTIR analysis}

FTIR spectra of different oils and epoxidised derivatives are shown in Figure 6. Main IR peaks and their corresponding functional groups of oil are listed below. 


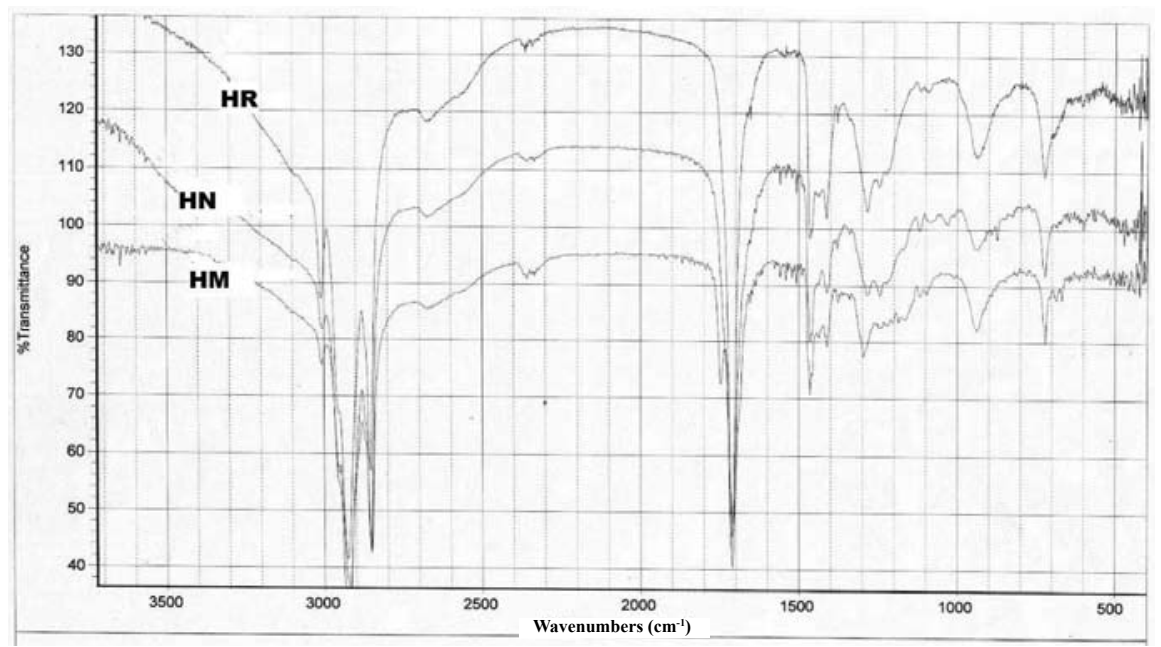

Figure 7: FTIR spectra of hydrolysed products of oils (HR=Hydrolyzed rubber seed oil, $\mathrm{HN}=$ Hydrolysed neem oil, $\mathrm{HM}=$ Hydrolyzed mee oil)

Table 5: Extent of epoxidation of virgin oils - (small scale, reaction carried out at $60{ }^{\circ} \mathrm{C}$ for 5 hours)

\begin{tabular}{lccc}
\hline Type of oil & $\begin{array}{c}\text { Iodine value of } \\
\text { epoxidised oil }\end{array}$ & \multicolumn{2}{c}{ Extent of epoxidation\% } \\
\cline { 3 - 4 } & 8.5 & 100 & Expected \\
Rubber seed oil & 7.1 & 100 & 100 \\
Neem oil & 4.1 & 100 & 88 \\
Mee oil & & 91 \\
\hline
\end{tabular}

Table 6: Extent of epoxidation of hydrolysed products of oils - (small scale, 5 hours at $60^{\circ} \mathrm{C}$ )

\begin{tabular}{lcccc}
\hline Type of oil & $\begin{array}{c}\text { Iodine value of } \\
\text { hydrolysed product }\end{array}$ & $\begin{array}{c}\text { Iodine value of hydrolysed } \\
\text { epoxidised product }\end{array}$ & \multicolumn{2}{c}{ \% Epoxidation } \\
Expected & Experimental \\
\hline Rubber seed oil & 119 & 6.6 & 100 & 94 \\
Neem oil & 91 & 5.7 & 100 & 94 \\
Mee oil & 60 & 5.5 & 100 & 91 \\
\hline
\end{tabular}

Table 7: NMR analysis of virgin oils and epoxidised oils

\begin{tabular}{lll}
\hline \multicolumn{1}{c}{$\delta \mathrm{ppm}$} & \multicolumn{2}{c}{ Peak assignment } \\
\cline { 2 - 3 } & Virgin oil & Epoxidised oil \\
\hline 0.8-0.9 (Triplet) & terminal $\mathrm{CH}_{3}$ & terminal $\mathrm{CH}_{3}$ \\
1.2-1.4 & $\mathrm{CH}_{2}$ protons in alkyl chain & $\mathrm{CH}_{2}$ protons in alkyl chain \\
$2.8-3.0$ (Quartet) & not observed & epoxy protons \\
2.5-3.0 I (Triplet) & $\mathrm{CH}_{2}$ protons adjacent to double bond & $\mathrm{CH}_{2}$ protons adjacent to epoxy group \\
4.1-4.4 (Double doublet) & $\mathrm{CH}_{2}$ protons in glycerol backbone & $\mathrm{CH}_{2}$ protons in glycerol backbone \\
5.1 & $\mathrm{CH}^{2}$ proton in glycerol back bone & $\mathrm{CH}_{\text {protons in glycerol back bone. }}$ \\
\hline
\end{tabular}

Table 8: Variation of the extent of epoxidation and iodine value with time

\begin{tabular}{lcccccc}
\hline $\begin{array}{l}\text { Reaction } \\
\text { time/h }\end{array}$ & \multicolumn{2}{c}{ Rubber seed oil } & \multicolumn{2}{c}{ Neem oil } & \multicolumn{2}{c}{ Mee oil } \\
Iodine value & Extent of epoxidation \% & Iodine value & Extent of epoxidation \% & Iodine value & Extent of epoxidation \% \\
\hline 2 & 32 & 73 & 12.1 & 80 & & \\
3 & 19 & 84 & 9.2 & 85 & 18.7 & 68 \\
4 & 13 & 89 & 7.4 & 88 & 14.7 & 75 \\
5 & 10 & 91 & 7.1 & 88 & 9.5 & 82 \\
6 & - & - & 6.8 & 89 & 7.9 & 88 \\
\hline
\end{tabular}


Frequency range $\left(\mathrm{cm}^{-1}\right)$ Assignment

2850-2860

C-H stretching of alkane

3010

$1745-1750$

1460-1465

$1115-1170$

720-725

$\mathrm{C}-\mathrm{H}$ stretching of non conjugated unsaturation

$\mathrm{C}=\mathrm{O}$ stretching of esters.

$\mathrm{C}-\mathrm{H}$ bending of unsaturated alkane

C-O stretching of esters

$\mathrm{C}-\mathrm{C}$ bending of saturated $\mathrm{C}$ atoms

Following are the characteristics of the FTIR spectra of epoxidised oils, which confirm that epoxidation has taken place.

- Disappearance of the band at $3010 \mathrm{~cm}^{-1}$ : shows $\mathrm{C}=\mathrm{C}$ has been used up.

- The appearance of a band around 820-830 $\mathrm{cm}^{-1}$, which is not seen in pure oils, is characteristic of the epoxide and it can be assigned to ring vibrations of the epoxy ring in $c i s$-epoxides ${ }^{29}$

Hydrolysed products are characterised by the reduction of carbonyl stretching frequency due to the hydrolysis and the peaks around 940 and $1300 \mathrm{~cm}^{-1}$ for C-O in ester and carboxylic acid, respectively (Figure 7). In general, the stretching frequency of the carbonyl group is reduced when ester is hydrolysed to form carboxylic acid.

\section{NMR analysis}

The proton NMR spectra of virgin neem oil and the epoxidised neem oil are shown in Figure 8. The conversion of olefinic group to epoxy group is clearly indicated by the spectra. The epoxy protons are observed at 2.8-3.0 ppm in all spectra of epoxidised oils, whereas olefinic protons appear in the region 5.2-5.4 ppm in spectra of virgin oils. This peak is not visible /weakly observed (due to traces of unreacted groups left) in spectra of epoxidised oils. Both peaks have appeared as a quartet due to the coupling of adjacent two protons of the $\mathrm{CH}_{2}$ group and the cis coupling of the proton attached to the next $\mathrm{sp}^{2}$ hybridised carbon atom. The terminal methyl group has appeared as a triplet in the range $0.7-1.0 \mathrm{ppm}$ in all spectra. The methyl proton of the $\mathrm{CH}$ backbone of the glycerol carbon is observed at $5.1 \mathrm{ppm}$ as a triplet in both cases, whereas the adjacent methyl protons give a characteristic double doublet pattern between 4.1-4.35 ppm, which is common for both epoxidised and virgin oils. On the other hand $\mathrm{sp}^{2}$ hybridised carbon in olefinic groups has appeared in the range $125-130 \mathrm{ppm}$ in 13-C NMR spectra of virgin Neem oil which is not observed in epoxidised Neem oil (Figure 9). Instead, peaks which have appeared in the range 50-60 ppm show the epoxy carbon atoms. Table 7 summarises the above data. The structure of a possible triglyceride in oils and its epoxidised product are shown in Figure 10 for easy identification of the nature of the aforementioned features, which are common for rubber seed oil, mee oil and their epoxidised products.

\section{Optimisation of the reaction time}

Variation of extent of epoxidation and the variation of iodine value with time is illustrated in Figure 11. According to the results, more than $75 \%$ epoxidation has taken place within a 3 hour time period at $60{ }^{\circ} \mathrm{C}$. Initially, with the higher concentration of reactants, the rate of epoxidation is high, but with decreasing concentration of reactants, rate becomes slow. It is clear that nearly $75 \%$ of the reaction is completed within 3 hours. To complete the last $25 \%$ of the reaction further 3 hours or more is necessary. Therefore, it is not cost-effective to spend that much of time and energy to achieve complete epoxidation and a reaction time of 3 hours could be considered as the optimum duration for the reaction. The TLC analysis of the products at different time intervals (Figure 12) also indicates steady increase in concentration of the product with time. The same pattern of reactivity was observed with the epoxidation of hydrolysed products, and the results are summarised in Table 9. The extent of epoxidation for all hydrolysed oil derivatives reached $90 \%$. It was also noted that more than $75 \%$ of epoxidation could be achieved within a 3-hour reaction time at $60{ }^{\circ} \mathrm{C}$ (Table 9). Further, these observations show that there is a possibility of controlling the extent of epoxidation by controlling the reaction time.

\section{Controlling the extent of epoxidation}

Previous studies ${ }^{4}$ have reported the kinetics of the epoxidation reaction with peroxy acetic acid and peroxy formic acid. It is pseudo-first order with respect to double bonds and hydrogen peroxide. Accordingly, the rate equation of the epoxidation can be written as

Rate $=k[$ Doublebond $]=\left[\mathrm{H}_{2} \mathrm{O}_{2}\right]$

Therefore, it is possible to control the extent of epoxidation by controlling reagents $\left(\mathrm{HCOOH}, \mathrm{H}_{2} \mathrm{O}_{2}\right)$.

Table 9: Variation of extent of epoxidation of hydrolysed oils

\begin{tabular}{cccc}
\hline Reaction time at & \multicolumn{3}{c}{ Extent of epoxidation \% } \\
$50-60^{\circ} \mathrm{C} / \mathrm{h}$ & $\begin{array}{c}\text { Hydrolysed } \\
\text { rubber seed oil }\end{array}$ & $\begin{array}{c}\text { Hydrolysed } \\
\text { neem oil }\end{array}$ & $\begin{array}{c}\text { Hydrolysed } \\
\text { Madhuca } \text { oil }\end{array}$ \\
\hline 2 & 75 & 69 & 79 \\
3 & 83 & 77 & 85 \\
4 & 81 & 83 & 89 \\
5 & 86 & 86 & 90 \\
\hline
\end{tabular}



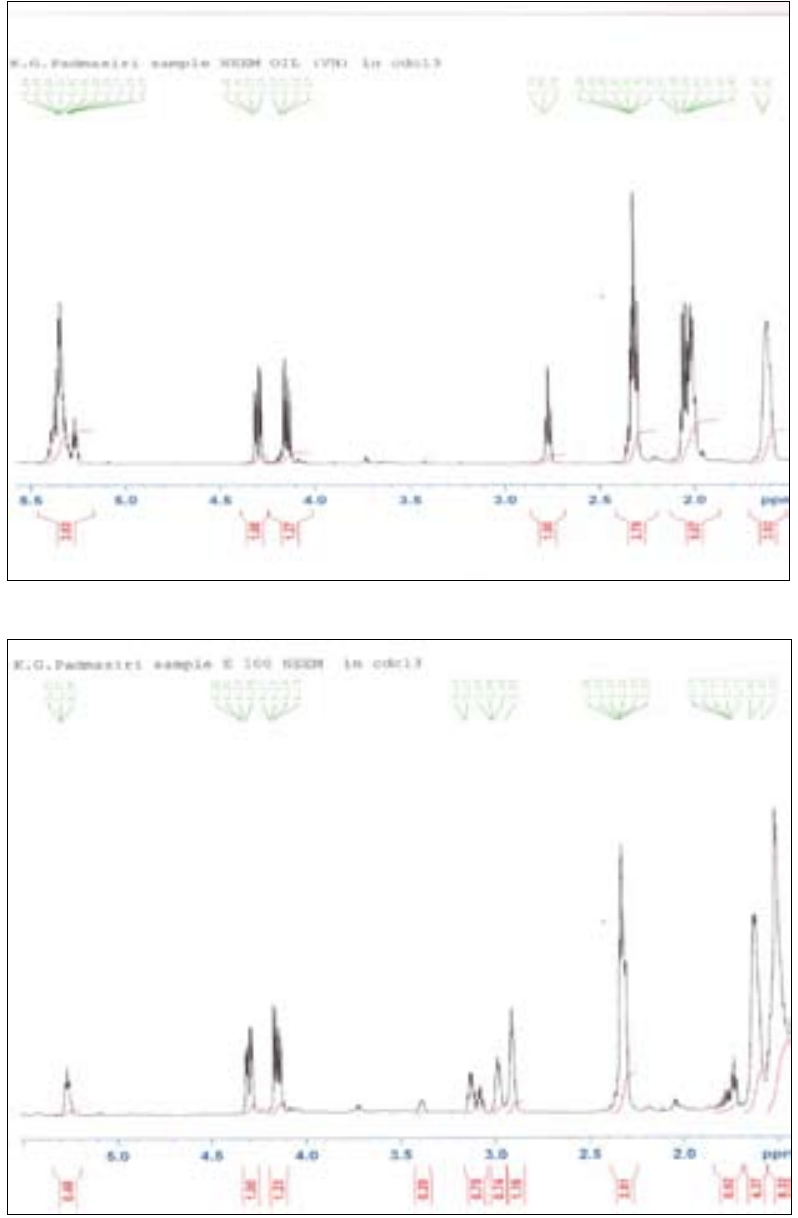

Figure 8: NMR spectra of neem oil (top) and epoxidised neem oil (bottom)

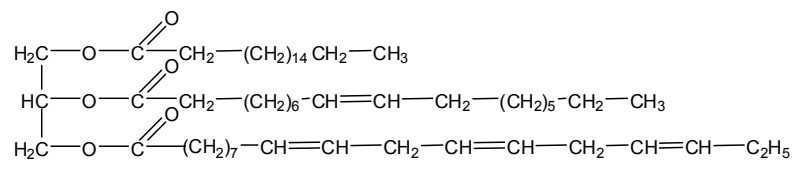

triglyceride

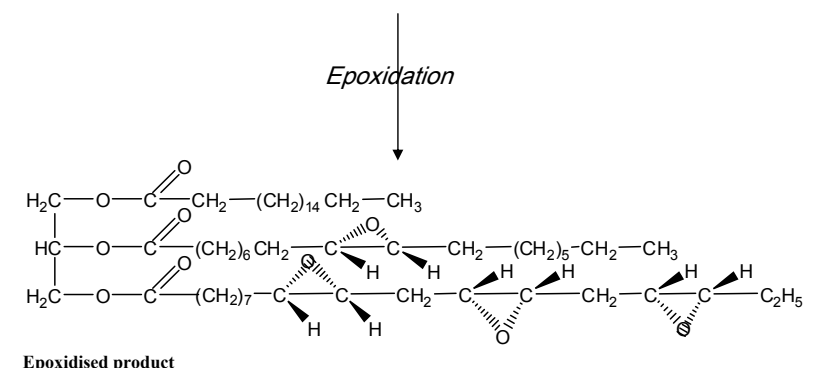

Figure 10: Structure of a possible triglyceride in oil and its epoxidised product
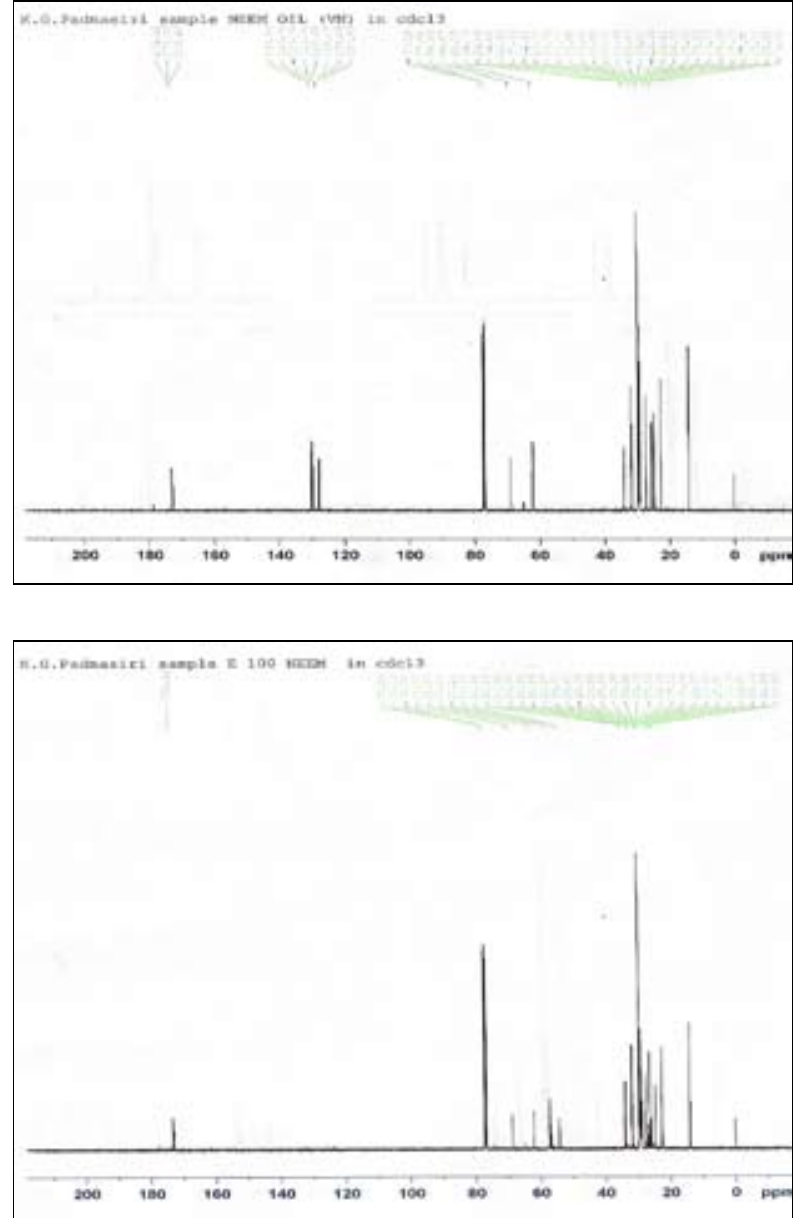

Figure 9: ${ }^{13} \mathrm{C}$ NMR spectra of neem oil (top) and epoxidised neem oil (bottom)

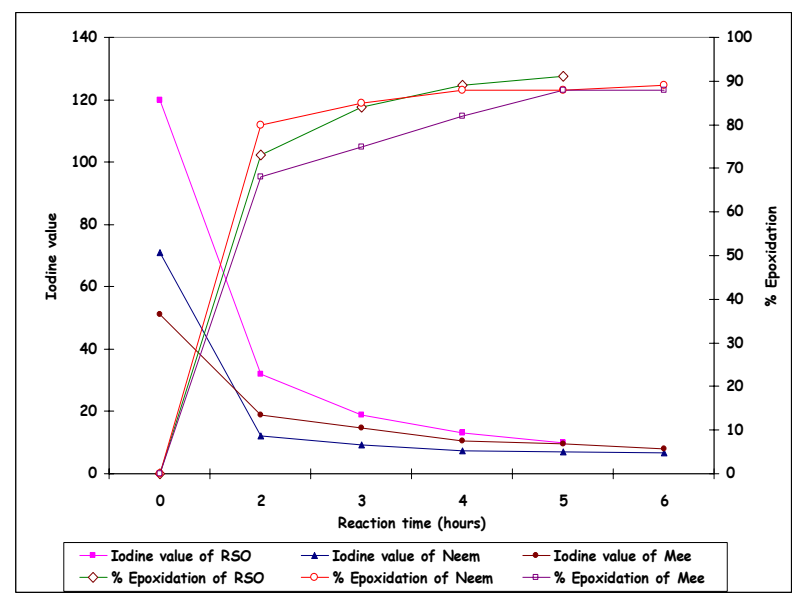

Figure 11: Variation of iodine values and $\%$ epoxidation of rubber seed oil, neem oil and mee oil with time 
Table 10: Epoxidation by controlling the reagents - reaction time $5 \mathrm{~h}$

\begin{tabular}{lcrc}
\hline Type of oil & Iodine value & \multicolumn{2}{c}{$\%$ Epoxidation } \\
& & Expected & Experimental \\
\hline \multirow{2}{*}{ Rubber seed oil } & 10 & 100 & 91 \\
& 46 & 50 & 63 \\
\multirow{4}{*}{ Neem oil } & 77 & 25 & 38 \\
& 7 & 100 & 88 \\
& 41 & 50 & 42 \\
Madhuca oil & 51 & 25 & 28 \\
& 10 & 100 & 88 \\
& 30 & 50 & 41 \\
& 38 & 25 & 26 \\
\hline
\end{tabular}

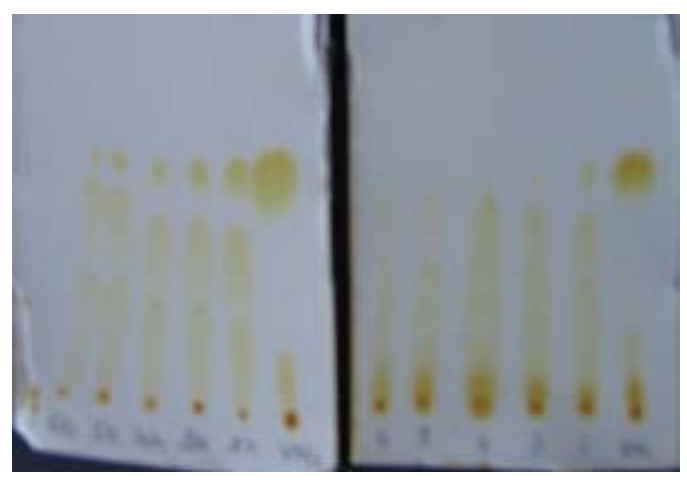

Figure 12: Extent of epoxidation with time for mee oil (left slide) and neem oil (right side). Spot at the right side of the slide is for the virgin oil. Other spots right to left are for the product at $2 \mathrm{~h}, 3 \mathrm{~h}$, $4 \mathrm{~h}, 5 \mathrm{~h}$ and $6 \mathrm{~h}$, time intervals.

Theoretically, the rate of the reaction could be lowered by $50 \%$, if the amount of $\mathrm{H}_{2} \mathrm{O}_{2}$ is halved. Nevertheless, the expected degree of epoxidation is not exactly met (Table 11). Values are quite close to the expected values in the case of oils with low iodine values (i.e. oils with less number of moles of unsaturations per unit mass). With increasing number of moles of unsaturation, i.e. rubber seed oil, the experimental value is always higher than the expected. This could be due to more effective collisions between reactant molecules when the reacting sites are higher. However, the extent of epoxidation was convincingly controlled by restraining the reagents, $\mathrm{H}_{2} \mathrm{O}_{2}$ and $\mathrm{HCOOH}$.

\section{Large scale epoxidation}

Large-scale epoxidation was attempted with a reaction time of $3 \mathrm{~h}$. No extraction procedures were utilised to isolate or purify the product, hence the method is simple, easy, and cost effective. Twelve oil derivatives were prepared in this manner as illustrated in the flow
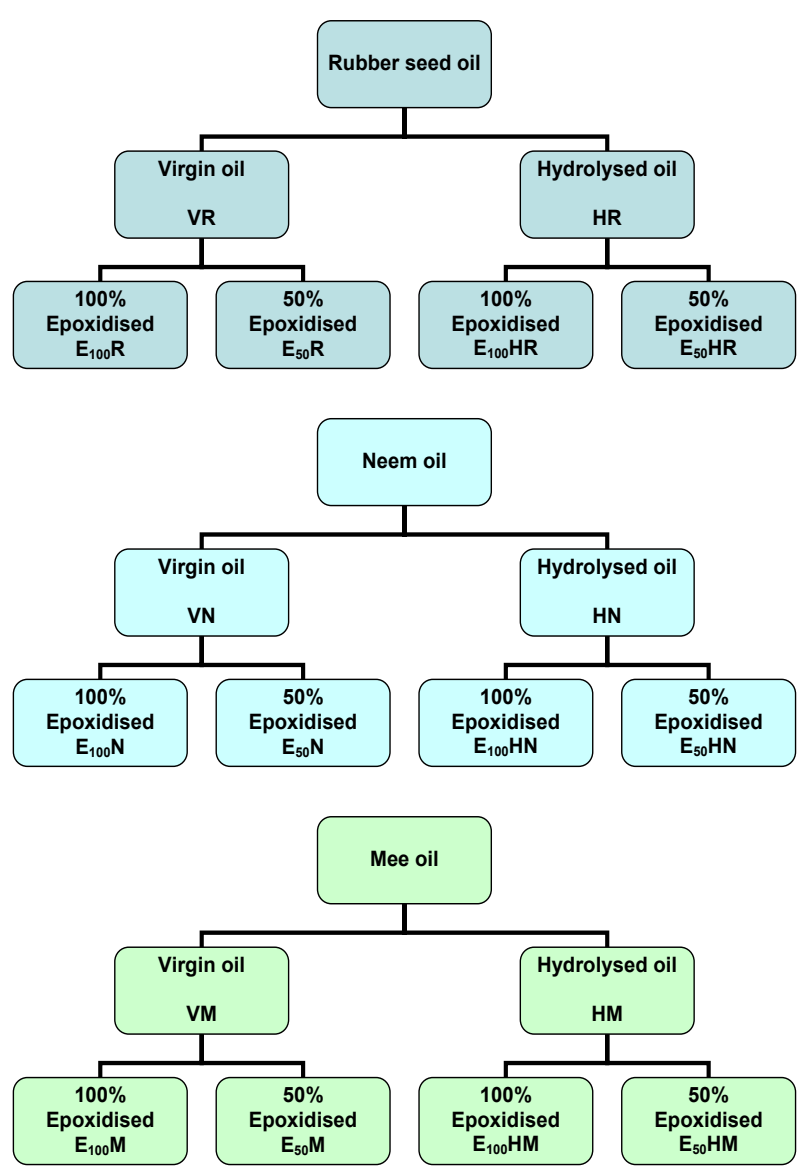

Figure 13: Epoxidised oil derivatives prepared from each oil

chart in Figure 13. Products were characterised for their iodine value and oxirane content (see Table 11). Other physical properties such as density, viscosity, and molar mass were also determined. The fatty acid profile of oils and the general structure of a glyceride were taken into consideration when estimating molar masses of oils and their epoxidized products.

\section{Solubility parameters}

Solubility parameters were calculated from the molar attraction constant values $G$, using Small's equation (Equation 1$)^{21}$. The $\chi$ values were then subsequently determined using Equation 2 with respect to PVC. Values thus obtained are delineated in Table 12. The thermodynamic concept for miscibility and the compatibility is that the smaller the difference between solubility parameters, the higher the miscibility of the components. The $\delta$ values obtained for oils and epoxidised oils are in good agreement with that of conventional plasticisers such as di-2-(ethyl) hexylphthalate used in PVC formulations (see Table 13) ${ }^{30}$. 
Table 11: Characterisations of prepared oil derivatives

\begin{tabular}{lllcrr}
\hline Sample identity & Nature/ Colour & $\begin{array}{c}\text { Density } \\
\mathrm{g} / \mathrm{cm}^{-3} / \mathrm{g} / \mathrm{cm}^{3}\end{array}$ & Iodine value & \% Epoxidation & Oxirane content \% \\
\hline $\mathrm{HR}$ & blackish brown oil & - & 136 & - & - \\
$\mathrm{E}_{100} \mathrm{R}$ & dark brown oil & 0.9864 & 34.5 & 75 & 3.1 \\
$\mathrm{E}_{50} \mathrm{R}$ & dark brown oil & 0.9750 & 66 & 47 & 1.7 \\
$\mathrm{E}_{100} \mathrm{HR}$ & dark brown oil & 0.9823 & 20 & 85 & 3.25 \\
$\mathrm{E}_{50} \mathrm{HR}$ & dark brown oil & 0.9774 & 56 & 57 & 1.65 \\
$\mathrm{HN}$ & yellowish brown oil & - & 93 & - & - \\
$\mathrm{E}_{100} \mathrm{~N}$ & yellow oil & 0.9770 & 07 & 94 & 3.21 \\
$\mathrm{E}_{50} \mathrm{~N}$ & yellow oil & 0.9513 & 35 & 51 & 1.58 \\
$\mathrm{E}_{100} \mathrm{HN}$ & yellow oil & 0.9712 & 08 & 91 & 2.4 \\
$\mathrm{E}_{50} \mathrm{HN}$ & yellow oil & 0.9436 & 33 & 64.5 & 1.9 \\
$\mathrm{HM}$ & dirty green oil & - & 67 & - & - \\
$\mathrm{E}_{100} \mathrm{M}$ & yellow oil & 0.9396 & 14 & 78 & 3.64 \\
$\mathrm{E}_{50} \mathrm{M}$ & yellow oil & 0.9042 & 35 & 31 & 1.25 \\
$\mathrm{E}_{100} \mathrm{HM}$ & yellow oil & 0.9363 & 09 & 87 & 3.5 \\
$\mathrm{E}_{50} \mathrm{HM}$ & yellow oil & 0.9201 & 30 & 54.5 & 1.52 \\
\hline
\end{tabular}

All oil derivatives were solidified on standing

Table 12: Solubility parameters and other data of oil derivatives

\begin{tabular}{lcccc}
\hline Oil /Oil derivatives & $\begin{array}{c}\text { Molar mass } \\
\mathrm{g} / \mathrm{mol}\end{array}$ & $\begin{array}{c}\text { Molar volume } \\
\mathrm{cm}^{3} / \mathrm{mol}\end{array}$ & $\begin{array}{c}\delta\left(\mathrm{cal} / \mathrm{cm}^{3}\right)^{1 / 2} \\
\text { Small's method }\end{array}$ & $\chi$ \\
\hline $\mathrm{RSO}$ & 307.5 & 332.1 & 10.5 & 0.600 \\
$\mathrm{E}_{100} \mathrm{R}$ & 329.0 & 333.5 & 10.04 & 0.284 \\
$\mathrm{E}_{50} \mathrm{R}$ & 321.0 & 329.2 & 10.33 & 0.454 \\
$\mathrm{E}_{100} \mathrm{HR}$ & 294.0 & 299.3 & 8.38 & 1.020 \\
$\mathrm{E}_{50} \mathrm{HR}$ & 283.0 & 289.5 & 8.84 & 0.524 \\
Neem oil & 314.4 & 327.6 & 10.6 & 0.700 \\
$\mathrm{E}_{100} \mathrm{~N}$ & 330.4 & 338.2 & 9.97 & 0.257 \\
$\mathrm{E}_{50} \mathrm{~N}$ & 320.4 & 336.8 & 10.14 & 0.324 \\
$\mathrm{E}_{100} \mathrm{HN}$ & 292.0 & 300.7 & 8.47 & 0.912 \\
$\mathrm{E}_{50} \mathrm{HN}$ & 287.4 & 304.6 & 8.45 & 0.945 \\
$\mathrm{Mee}$ oil & 316.0 & 346.3 & 10.06 & 0.300 \\
$\mathrm{E}_{100} \mathrm{M}$ & 325.4 & 346.3 & 9.90 & 0.235 \\
$\mathrm{E}_{50} \mathrm{M}$ & 320.0 & 353.9 & 10.06 & 0.735 \\
$\mathrm{E}_{100} \mathrm{HM}$ & 288.4 & 308.0 & 8.44 & 0.967 \\
$\mathrm{E}_{50} \mathrm{HM}$ & 284.5 & 309.2 & 8.48 & 0.920 \\
\hline
\end{tabular}

$\mathrm{RSO}=$ rubber seed oil

Table 13: Solubility parameter values and molar volumes for some plasticisers at $25^{\circ} \mathrm{C}$ calculated by Small's method ${ }^{30}$

\begin{tabular}{lcc}
\hline Plasticiser & $\delta\left(\mathrm{cal}^{1 / 2} \mathrm{ml}^{-1 / 2}\right)$ & $\begin{array}{c}\text { Molar } \\
\text { volume }(\mathrm{mL})\end{array}$ \\
\hline tolyl diphenyl phosphate & 10.2 & 280 \\
triphenyl phosphate & 9.9 & 274 \\
di-n-butyl phthalate & 9.3 & 269 \\
di-n-hexyl phthalate & 9.1 & 334 \\
di-2-ethylhexyl phthalate (DOP) & 8.8 & 398 \\
di-n-octylphthalate & 8.9 & 401 \\
di-2-ethylhexyl adipate & 8.6 & 401 \\
di-2-ethylhexyl azealate & 8.4 & 451 \\
di-2-ethylhexyl sebacate & 8.5 & 469 \\
\hline
\end{tabular}




$$
\delta=\frac{d}{M} \sum G
$$

\section{Equation 1}

$$
\chi_{1}=\chi_{s}+\frac{V_{1}\left(\delta_{L}-\delta_{P}\right)^{2}}{R T}
$$

\section{Equation 2}

Where $d$ is the density; $M$ is the molar mass of the substance;

$\chi_{\mathrm{s}}$ is an entropic term (usually assigned a value of 0.2 ). $V_{1}$ is the molar volume. $\delta_{\mathrm{L}}$ and $\delta_{\mathrm{p}}$ are the solubility parameters for the liquid and polymer, respectively. $R$ is the gas constant and $T$ is the absolute temperature.

These results suggest that epoxidised oils of rubber, Neem and Mee, which are derived from renewable sources, could be effectively used in PVC industry as an option for conventional petroleum based plasticisers.

\section{CONCLUSION}

Rubber seed oil, Madhuca oil (Mee oil) and Neem oil and their hydrolysed products were epoxidised successfully by peroxyformic acid generated 'insitu' by reacting formic acid (methanoic acid) with hydrogen peroxide at the temperature range $50-60{ }^{\circ} \mathrm{C}$. The epoxidation was confirmed by Iodine value, TLC analysis, FTIR analysis and NMR analysis. It was found that more than $75 \%$ of the reaction was completed within three hours at $60{ }^{\circ} \mathrm{C}$. The level of epoxidation could be controlled reasonably by controlling the amount of reagents. Lower levels of epoxidation could be achieved well with RSO and Neem oil, which have higher iodine values, by controlling the reagent. Optimised reaction conditions were utilised in large-scale epoxidation of oils and hydrolysed products of oils without solvent extraction procedures. Solubility parameters of oils and epoxidised oils were determined and values obtained were found to be in the range of those of conventional plasticisers used in the PVC industry. This will lead to a more convenient and economically viable method for large-scale epoxidation of vegetable oils, which could be useful especially in plasticiser/ stabiliser industry.

\section{Acknowledgement}

The financial assistance from the National Science Foundation of Sri Lanka through the grant RG/2006/ FR/03 is gratefully acknowledged.

\section{References}

1. Parreira T.F., Ferreira M.M.C., Sales H.J.S. \& De Almeida W.B. (2002). Quantitative determination of epoxidised soybean oil using near infrared spectroscopy and multivariate calibration. Applied Spectroscopy 56(12): 1607-1614.

2. March J. (1992). Addition to carbon-carbon multiple bonds. In: Advanced Organic Chemistry: Reactions Mechanisms and Structures. $4^{\text {th }}$ edition, pp. 826-827. John Wiley and Sons, USA.

3. Vijayagopalan K. \& Gopalakrishnan K.S. (1971). Epoxidation of rubber seed oil. Rubber Board Bulletin 11(2): 52-54.

4. Petrovic Z.S., Zlatanic A., Lava C.C. \& Sinadinovic-fise S. (2002). Epoxidation of soya bean oil in toluene with peroxoacetic acid and peroxoformic acids-kinetics and side reactions. European Journal of Lipid Science and Technology 104(5):293-299.

5. Okieimen F.E., Bakare O.J. \& Okieimen C.O. (2002). Studies on the epoxidation of rubber seed oil. Industrial Crops Production 15(2): 139-144.

6. Ishiaku U.S., Shaharum A., Ismail H. \& Mohd.Ishak Z.A. (1997). The effect of an epoxidised plasticizer on the thermo-oxidative ageing of PVC/ENR thermoplastic elastomer. Polymer International 45(1): 83-91.

7. Gan L.H., Oii K.S., Goh S.H., Gan L.M. \& Leong Y.C. (1995). Epoxidised esters of palm olein as plasticizer for PVC. European Polymer Journal 31(8): 719-724.

8. US patent 6797753 . Plasticisers derived from vegetable oils.

9. Whelmann J. (1999). Use of esterified rapeseed oil as plasticizer in plastic processing. Fett/Lipid 101(6): 249256.

10. Okieimen F.E. \& Eromonsele O.C. (2000). Stabilising effect of derivatives of Khaya seed oil on the thermal degradation of poly (vinyl chloride). European Polymer Journal 36(3):525-537.

11. Okieimen F.E. \& Ebboye J.E. (1993). Studies in thermal degradation of PVC. Journal of Applied Polymer Science 48(10): 1853-1858.

12. Benaniba M.T., Belhaneche-Bensmera N. \& Gelbard G. (2001). Stabilising effect of epoxidised sunflower oil on the thermal degradation of poly(vinyl chloride). Polymer Degradation and Stabilization 74(3): 501-505.

13. Joseph R., Madhusoodhanam K.N., Alex R., Varghese S., George K. E. \& Kuriakose B. (2004). Studies on epoxidised rubber seed oil as secondary plasticiser/ stabiliser for polyvinylchloride. Plastic and Rubber Composites 33(5): 217-222.

14. Okieimen F.E. (2002). Studies in the utilization of epoxidised vegetable oils as thermal stabilizer for polyvinyl chloride. Industrial Crops and Production 15(1): 71-75.

15. Egbuchunam T.O., Balkose D. \& Okieimen F.E. (2007). Effect of zinc soaps of rubber seed oil (RSO) and / or epoxidised rubber seed oil (ERSO) on the thermal stability of PVC plastigels. Polymer Degradation and Stabilization 92(8): 1572-1582. 
16. http://en.wikipedia.org/wiki/neem_oil. Accessed in october 2007.

17. Standard methods for the analysis of oils (1994). In: Fats and Derivatives part I, section II, $6^{\text {th }}$ edition, pp. 66-70, 92-94 Pergamon Press, Paris, France.

18. Jeffery G.H., Basset J., Mendham J. \& Denny R.C. (1994). Complexation titrations. In: Vogel's Textbook of Quantitative Chemical Analysis $5^{\text {th }}$ edition. pp. 309-321, Longman Publishers, Essex, UK.

19. Okieimen F.E., Pavithran C. \& Bakare I.O. (2005). Epoxidation and hydroxylation of rubber seed oil: one - pot multi-step reactions. European Journal of Lipid Science and Technology 107(5): 330-336.

20. Gunstone F.D. (2004). Oils and fats: sources and constituents. In: The Chemistry of Oils and Fats, Sources, Composition Properties and Uses. pp.10-35, Blackwell Publishers, Oxford, UK.

21. Carraher C.E. Jr (2003). Plasticisers, stabilizers, flame retardents and other additives. In: Seymour/Carraher's Polymer Chemistry, 6 ${ }^{\text {th }}$ edition. pp. $534-555$, Marcel Decker Inc., New York, USA.

22. Mathews G. (1996). Principles of formulation. In: $P V C$ Production, Properties and Uses. pp.147-156. The Institute of Materials, London, UK.
23. Gachter R. \& Muller H. (1996). Plastic Additives Handbook. pp. 145-165, Hanser Publishers, New York, USA.

24. Joseph R., Madhusoodhanam K.N., Alex R., Varghese S., George K.E. \& Kuriakose B. (2004). Studies on epoxidised rubber seed oil as secondary plasticiser/ stabiliser for polyvinylchloride. Plastics, Rubber and Composites 33(05): 217-222.

25. http://neem-composition.htm. Accessed in September 2007.

26. www.ieindia.org/publish. Accessed in October 2006.

27. Ramadhas A.S., Jayaraj S.W. \& Muraleedharan C. (2005). Characterisation and effect of using rubber seed oil as fuel in the compression ignition engines. Renewable Energy 30(5): 795-803.

28. Ghadge S.V. \& Raheman H. (2005). Biodiesel production from mahua (Madhuca indica) oil having high free fatty acids. Biomass and Bioenergy 28(6): 601-605.

29. Bellamy L.J. (1975). The infrared spectra of complex molecules. In: Ethers, Peroxides and Ozonides Volume I, $3^{\text {rd }}$ edition., pp. 133-135. Methuen and Company Ltd. London, UK.

30. Ritchie P.D. (1972). Compatibility,efficiency and permanence of plasticisers In: Plasticisers, Stabilisers, and Fillers. pp. 59-78. ILIFE Books Ltd., London, UK. 